\title{
Correction to: eDNA and metabarcoding for rewilding projects monitoring, a dietary approach
}

\author{
Laura lacolina ${ }^{1,2,5}$ - Mie Bech Lukassen ${ }^{1} \cdot$ Camilla Fløjgaard $^{3} \cdot$ Rita Buttenschøn $^{4} \cdot$ Jeppe Lund Nielsen ${ }^{1}$. \\ Cino Pertoldi ${ }^{1,2}$
}

Published online: 25 August 2020

(c) Deutsche Gesellschaft für Säugetierkunde 2020

\section{Correction to: Mammalian Biology (2020) 100:411-418 https://doi.org/10.1007/s42991-020-00032-y}

The original version of this article unfortunately contained a mistake. The Electronic Supplementary Material was missing in the online version. The ESM is available in the online version of this correction article.

Publisher's Note Springer Nature remains neutral with regard to jurisdictional claims in published maps and institutional affiliations.

The original article can be found online at https://doi.org/10.1007/ s42991-020-00032-y.

Electronic supplementary material The online version of this article (https://doi.org/10.1007/s42991-020-00061-7) contains supplementary material, which is available to authorized users.

Laura Iacolina

lauraiacolina@gmail.com

Mie Bech Lukassen

mbl@bio.aau.dk

Camilla Fløjgaard

camf@bios.au.dk

Rita Buttenschøn

rmb@ign.ku.dk

Jeppe Lund Nielsen

jln@bio.aau.dk

Cino Pertoldi

cp@bio.aau.dk
1 Department of Chemistry and Bioscience, Aalborg University, Fredrik Bajers Vej 7H, 9220 Aalborg, Denmark

2 Aalborg Zoo, Mølleparkvej 63, 9000 Aalborg, Denmark

3 Department of Bioscience Kalø, Aarhus University, Grenåvej 14, 8410 Rønde, Denmark

4 Department of Geosciences and Natural Resource Management, Copenhagen University, Rolighedsvej 23, 1958 Frederiksberg, Denmark

5 Present Address: Faculty of Agriculture, Department of Apiculture, Wildlife Management and Special Zoology, University of Zagreb, Svetošimunska cesta 25, 10000 Zagreb, Croatia 